\title{
ОСОЗНАННАЯ САМОРЕГУЛЯЦИЯ И СУБЪЕКТИВНОЕ БЛАГОПОЛУЧИЕ МЛАДШИХ ПОДРОСТКОВ: ЛОНГИТЮДНОЕ ИССЛЕДОВАНИЕ ${ }^{17}$
}

\author{
Фомина Т.Г., Моросанова В.И. (ФГБНУ «Психологический институт \\ Российской академии образования», Москва, Россия) \\ tanafomina@mail.ru,morosanova@mail.ru

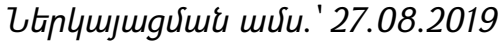

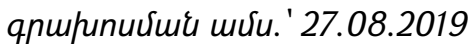

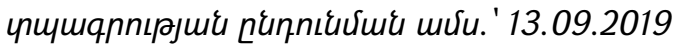

В статье представлены эмпирические результаты исследования взаимосвязи осознанной саморегуляции учебной деятельности и субъективного благополучия младших подростков в школьной среде. Диагностика включала оценивание регуляторных процессов и регуляторноличностных свойств (опросник В.И. Моросановой «Стиль саморегуляции учебной деятельности, ССУД-М»), а также показателей удовлетворенности жизнью учащихся («Многомерная детская шкала удовлетворённости жизнью (ШУДЖИ)»). Выборку исследования составили учащиеся 4-6 классов российских школ $(\mathrm{N}=515)$. Проведен анализ значимых предикторов субъективного благополучия для школьников разных классов. Получены результаты, согласно которым, общий уровень саморегуляции и отдельные регуляторные характеристики являются значимыми предикторами субъективного благополучия учащихся, описана их специфика для 4, 5, 6 классов. Перекрестно-лонгитюдный анализ позволил установить, что осознанная саморегуляция выступает значимым предиктором устойчивости субъективного благополучия учащихся при переходе из начальной в основную школу, то есть выступает надежным предиктором благополучия в последующих возрастах.

Ключевые слова: осознанная саморегуляция, субъективное благополучие, младшие подростки.

В последние годы существенно увеличилось количество исследований, ориентированных на решение теоретических и практических вопросов, связанных с проблемой субъективного благополучия учащихся. Низкий уровень субъективного благополучия подростков - стабильно воспроизводимый результат исследований в разных странах [5]. Удовлетворенность жизнью положительно связана с прогнозом академической успешности, позитивными отношениями с окружающими, более низким проявлением стресса в академической среде и является защитным фактором негативного воздействия на здоровье подростков [10]. В настоящее

17 Исследование выполнено при финансовой поддержке РффИ в рамках научного проекта № 17-36-00037 
время исследователей интересует вопрос не только о том, какие психологические механизмы влияют на субъективное благополучие школьников, но и то какие из них могут рассматриваться в качестве надежных долгосрочных предикторов благополучия в последующих возрастах.

О необходимости изучения психологических механизмов, которые формируются в детском и подростковом возрасте и являются основой психологического благополучия взрослых, заявляют многие исследователи [8]. Отмечается, что наиболее перспективными в этом отношении являются личностные черты, самоконтроль и саморегуляция.

Термин саморегуляция используется для объяснения широкого спектра человеческого поведения в самых разных контекстах. Теоретическим основанием наших исследований является представление об осознанной саморегуляции как многоуровневой и динамической системе процессов, состояний и свойств, которые являются инструментом инициации и поддержания активности, направленной на осознанное выдвижение и достижение субъектных целей. Мы рассматриваем осознанную СР как интегративный когнитивно-личностный конструкт, включающий систему когнитивных процессов переработки информации (планирование целей, моделирование значимых для их достижения условий, программирование действий, оценивание результатов) и инструментальных личностно-регуляторных свойств (гибкость, самостоятельность, надежность, ответственность и др.) [1].

Школьное благополучие характеризует позитивное восприятие учебы, школы, а также своего академического потенциала. Немногочисленные исследования субъективного благополучия детей младшего школьного возраста показывают, что у младших школьников понимание счастья во многом связано с успешным осуществлением учебной деятельности. В свою очередь в своих исследованиях мы эмпирически доказали значимое влияние осознанной саморегуляции на эфрфективность учебной деятельности [4]. В связи с этим можно предположить, что саморегуляция - значимый ресурс поддержания субъективного благополучия учащихся. К Концу начальной школы у учащихся фрормируются субъектные качества, характеризующие инструментально-личностную специфику их саморегуляции. Среди них - регуляторная самостоятельность, ответственность, инициативность. Формирование этих качеств позволяет более эфрфективно справляться с новыми задачами учебной деятельности, что сказывается и на субъективном благополучии учащихся.

Переход из начальной школы в основную сопровождается кардинальной сменой условий обучения, которые предъявляют повышенные требования к субъектным качествам учащихся: самостоятельности, ответственности, инициативности. Ситуационные факторы учебной деятельности задают новый вектор в развитии учащихся. Эмпирические исследования, показывают, что возраст между 10 и 12 годами является переломным в становлении именно 
субъектной составляющей самосознания, происходит переход от внешнего к внутреннему локусу контроля, рефлексии как индивидуальной способности к самоизменению [9].

Наше исследование связано с выявлением взаимосвязи осознанной саморегуляции и субъективного благополучия учащихся в школьной среде, а также поиском ответа на вопрос, является ли саморегуляция ресурсом устойчивости субъективного благополучия учащихся на разных этапах школьного обучения. Мы организовали исследование, в котором было реализовано два дизайна: кросссекционный (cross-sectional design) и лонгитюдный (longitudinal panel design). B первом случае были исследованы регуляторные предикторы субъективного благополучия учащихся 4-6 классов, проведена их сравнительная характеристика. Во втором случае выборку составили учащиеся, которые на протяжении 3 лет (с 4 по 6 класс) принимали участие в обследовании. Это позволило ответить на вопросы о динамике осознанной саморегуляции и субъективного благополучия учащихся при переходе из начальной в основную среднюю школу, выявить перекрестнолонгитюдные связи и оценить прогностические эфффекты.

Выборку исследования составили учащиеся 4-6 классов российских школ (515 человек). Учащиеся 4 классов: 156 человек, средний возраст 10,3 г. (стандартное отклонение 0,48), 71 мальчик (46\%), 85 девочек (54\%). Учащиеся 5-х классов: 188 человек, средний возраст 10,8 г. (стандартное отклонение 0.42), 96 мальчиков (51\%) и 92 (49\%) девочки. Учащиеся 6-х классов: 171 человек, средний возраст 11,9 г. (стандартное отклонение 0.32), 82 мальчика (48\%) и 89 девочек (52\%). Помимо кросс-секционного дизайна, наше исследование предполагало организацию лонгитюдного исследования. Соответственно выборка лонгитюдного исследования была скорректирована с учетом того, сколько детей заполнили опросники во всех трех точках лонгитюда: в 4 (Т1), 5 (Т2) и 6 (Т3) классе. Временные интервалы составили: между обследованиями в 4 (Т1) и 5 (Т2) классе - 7 месяцев, между 5 и 6 (Т3) - 1 год. Завершили опросы Т1, Т2, Т3 - 106 чел.

Методы исследования. Для диагностики регуляторных особенностей использовалась опросная методика «Стиль саморегуляции поведения (детский) ССПМ-Д» [2]. Данная методика была специально разработана для младших школьников. Вопросы представлены в виде описания типичных учебных, повседневных ситуаций, которые необходимо оценить, применительно к себе по 6бальной шкале. Оцениваются следующие регуляторные процессы и свойства: планирование, моделирование, программирование, оценивание результата, гибкость, самостоятельность, ответственность и общий уровень как сумма по всем шкалам.

Для оценки параметров субъективного благополучия школьников была использована «Многомерная детская шкала удовлетворённости жизнью (ШУДЖИ)», адаптация опросника MSLSS E.C. Хюбнера [6]. Мы использовали версию, в которой удовлетворенность жизнью оценивается по трем шкалам: «Семья» 
(удовлетворенность взаимоотношениями в семье); “Школа" (удовлетворенность детей школьной жизнью с точки зрения поддержки их интересов и общего отношения к школе и учебной деятельности) и «Я сам» (удовлетворенность самим собой, позитивное отношение к себе и мнениям других людей). Методика включает утверждения (по 7-8 на каждую шкалу), которые необходимо оценить по 5-бальной шкале ответов от «никогда» до “всегда». Значения коэффиициентов надежности $\alpha$ Кронбаха шкал методики на нашей выборке составили: шкала “Семья» - 0.840; шкала «Школа» - 0.886; шкала «Я сам» - 0.782.

Результаты Ранее уже показано в наших исследованиях, что осознанная саморегуляция значимо связана с различными проявлениями субъективного благополучия учащихся [3]. Здесь мы приведем данные регрессионного анализа и продемонстрируем специфику значимых регуляторных предикторов школьного благополучия учащихся в 4, 5 и 6 классах средней школы. В качестве зависимой переменной в регрессионных моделях выступал показатель субъективного благополучия в школе (шкала «Школа» методики MSLSS), независимых регуляторные процессы, свойства, а также общий уровень саморегуляции. В таблице 1 представлены итоговые регрессионные модели, в которых независимыми переменными были отдельные регуляторные показатели.

\begin{tabular}{|c|c|c|c|c|c|c|}
\hline Классы & $\begin{array}{l}\text { Зависимая } \\
\text { переменная }\end{array}$ & $\mathrm{R}^{2}$ & $\mathrm{~F}$ & $\begin{array}{l}\text { Значимые } \\
\text { предикторы }\end{array}$ & Бета & $\begin{array}{l}\text { Значи- } \\
\text { мость }\end{array}$ \\
\hline \multirow[t]{2}{*}{4 классы } & \multirow{2}{*}{$\begin{array}{l}\text { Субъективное } \\
\text { благополучие } \\
\text { в школе }\end{array}$} & \multirow[t]{2}{*}{.320} & \multirow[t]{2}{*}{9.691} & Планирование & .179 & .029 \\
\hline & & & & Моделирование & .304 & .000 \\
\hline \multirow[t]{2}{*}{5 классы } & \multirow{2}{*}{$\begin{array}{l}\text { Субъективное } \\
\text { благополучие } \\
\text { в школе }\end{array}$} & \multirow[t]{2}{*}{.256} & \multirow[t]{2}{*}{7.468} & Планирование & .244 & .003 \\
\hline & & & & Оценка результатов & .200 & .025 \\
\hline \multirow[t]{3}{*}{6 классы } & \multirow{3}{*}{$\begin{array}{l}\text { Субъективное } \\
\text { благополучие } \\
\text { в школе }\end{array}$} & \multirow[t]{3}{*}{.298} & \multirow[t]{3}{*}{9.165} & Планирование & .206 & .011 \\
\hline & & & & Программирование & .172 & .039 \\
\hline & & & & Ответственность & .305 & .000 \\
\hline
\end{tabular}

Регрессионный анализ свидетельствует, о том, что саморегуляция оказывается значимым предиктором школьного благополучия учащихся разных классов, то есть является устойчивым механизмом его поддержания в разные периоды школьного обучения. Кроме этого, можно отметить некоторые общие и некоторые специфичные различия между значимыми регуляторными предикторами благополучия учащихся разных классов. Так, вне зависимости от класса, регуляторный процесс планирования сохраняет свою значимость, что подчеркивает 
его ресурсную роль в этом возрасте. Для благополучия в школе четвероклассников специфическим предиктором оказался процесс моделирования значимых условий, пятиклассников - процесс оценивания результатов, для шестиклассников - процесс программирования и регуляторно-личностное свойство ответственности. Данные результаты свидетельствуют о том, что на разных этапах школьного обучения в связи с изменениями в организации учебного процесса, специфики решаемых задач меняется и роль отдельных регуляторных механизмов в обеспечении общего благополучия в школьной среде. Кроме этого, происходит возрастное формирование и совершенствование саморегуляции. Стоит отметить, что регрессионные модели с включением общего уровня саморегуляции для всех классов оказались значимы.

Для анализа данных мы использовали метод перекрестно-лонгитюдного анализа (a longitudinal cross-lagged analysis). Он применяется для оценки не только стабильности изучаемых признаков во времени через анализ одновременных взаимосвязей и общей вариации переменных внутри каждого из замеров, но и для объяснения причинно-следственных связей, показывающих, насколько вариация предшествующего измерения одного признака объясняет вариацию последующего измерения другого признака. В нашем исследовании использовалась 3-х волновая модель (3-wave longitudinal study). Для построения перекрёстно-лонгитюдной модели мы использовали показатель СБ учащихся, полученный для шкалы "Школа», а также показатель общего уровня осознанной саморегуляции учебной деятельности, соответственно измеренных в 4,5 и 6 классах (рис. 1).

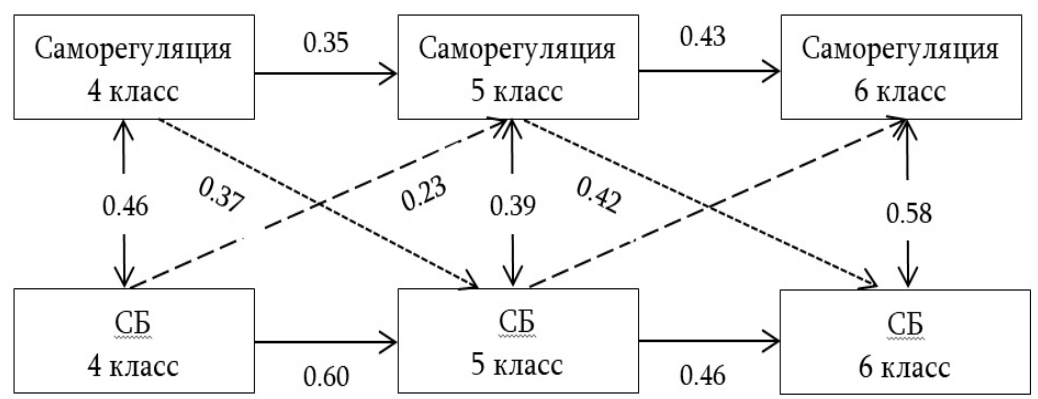

Рисунок 1. Перекрестно-лонгитюдная модель взаимосвязи общего уровня саморегуляции и субъективного благополучия учащихся.

СБ - субъективное благополучие; указаны значимые стандартизированные коэффициенты регрессии

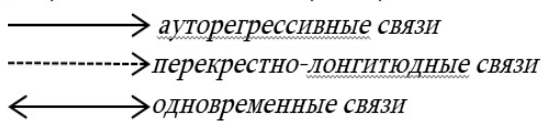

Представленная модель позволила оценить ауторегрессивные, одновременные и перекрестно-лонгитюдные связи. Ауторегрессивные коэфффициенты статисти- 
чески значимы, что свидетельствует о стабильности исследуемых переменных во времени. Одновременные связи подтверждают результаты о том, что в каждом возрастном срезе осознанная саморегуляция и субъективное благополучие значимо связаны. Оценка перекрестно-лонгитюдных связей показала, что статистически значимой является связь именно саморегуляции и субъективного благополучия, то есть более высокое развитие саморегуляции у учащихся в четвертом классе предсказывает благополучие учащихся в пятом классе, а затем и в шестом.

Таким образом, в проведенном исследовании подтвердились данные о том, что уровень развития осознанной саморегуляции выступает значимым предиктором субъективного благополучия учащихся 4-6 классов. Впервые на основе анализа перекрестно-лонгитюдных связей показано, что уровень развития осознанной саморегуляции учебной деятельности учащихся начальной школы предсказывает более высокий уровень их субъективного благополучия при переходе в среднюю школу: в 5 и 6 классах. Полученные результаты позволяют сделать значимый в теоретическом и практическом отношении вывод о том, что осознанная саморегуляция учебной деятельности является не только предиктором субъективного благополучия у младших школьников, но и ресурсом его устойчивости и роста в более поздних возрастах и при переходе на среднюю ступень обучения.

\section{Литература}

1. Моросанова В.И. Осознанная саморегуляция человека как психологический ресурс достижения учебных и профессиональных целей// Теоретическая и экспериментальная психология. 2014. №4. С.16-38.

2. Моросанова В.И., Бондаренко И.Н. Диагностика саморегуляции человека. М.: Когито-Центр, 2015. 304 с.

3. Моросанова В.И., Фомина Т.Г. Осознанная саморегуляция учебной деятельности как ресурс субъективного благополучия школьников при изменении условий обучения // Вопросы психологии. 2019. № 3. С.62-74.

4. Моросанова В.И., Фомина Т.Г. Осознанная саморегуляция в системе психологических предикторов достижения учебных целей // Вопросы психологии. 2016. №2. С.124-135.

5. Подольский А.И., Карабанова О.А., Идобаева О.А., Питер X. Психоэмоциональное благополучие современных подростков: опыт международного исследования // Вестник Московского университета. Серия 14: Психология. 2011. №. 2. С. 9-20.

6. Сычев О.А., Гордеева Т.О., Лункина М.В., Осин Е.Н., Сиднева А.Н. Многомерная шкала удовлетворенности жизнью школьников// Психологическая наука и образование . 2018 . Т . 23 . № 6 . С . 5-15 . doi: $10.17759 /$ pse .201823060. 
7. Фомина Т.Г., Ефтимова О.В., Моросанова В.И. Взаимосвязь субъективного благополучия с регуляторными и личностными особенностями у учащихся младшего школьного возраста [Электронный ресурс] // Психологопедагогические исследования. 2018. Том 10. № 2. С. 64-76 doi: 10.17759/psyedu.2018100206

8. Hampson S. E. Mechanisms by which childhood personality traits influence adult well-being //Current Directions in Psychological Science. 2008. Vol. 17. No. 4. pp. 264-268.

9. Lampropoulou A. Personality, school, and family: What is their role in adolescents' subjective well-being //Journal of adolescence. 2018. Vol. 67. pp. 12-21.

10. Ng Z. J., Huebner S. E., Hills K. J. Life satisfaction and academic performance in early adolescents: Evidence for reciprocal association //Journal of school psychology. 2015. Vol. 53. No. 6. pp. 479-491.

\section{CONSCIOUS SELF-REGULATION AND SUBJECTIVE WELL-BEING IN EARLY ADOLESCENCE: A LONGITUDINAL STUDY}

Fomina T.G., Morosanova V.I. (FGBNU «Psychological Institute of the Russian Academy of Education», Moscow, Russia)

The article presents research results on the relationship between conscious selfregulation of the learning activities and subjective well-being of the younger adolescents in the school environment. Diagnostics included assessment of the regulatory processes and intrapersonal-regulatory features ("Self-regulation of the Learning Activity Questionnaire", Morosanova, 2015) and certain aspects of the students' life satisfaction ("Multidimensional Children's Life Satisfaction Scale", Sytchev et al., 2018). The sample consisted of the 4-6 graders of the Russian schools ( $N=515)$. According to regression analysis results, the General level of self-regulation and particular individual regulatory characteristics turned to be significant predictors of the students' subjective well-being. Their specificity is described for the students of 4, 5, 6 grades. Cross-longitudinal analysis allowed to establish that conscious self-regulation of the learning activity is a significant predictor of the subjective well-being stability during the students' transition from the primary to the middle school, so it serves as a reliable predictor of the schoolchildren' well-being in subsequent ages.

Keywords: conscious self-regulation, subjective well-being, early adolescence. 